\title{
IN SITU MEASUREMENT OF BEDROCK EROSION
}

\author{
D. H. Rieke-Zapp ${ }^{\text {a, } *, \text { A. Beer }}{ }^{\text {b }}$, J. M. Turowski ${ }^{\text {b }}$, L. Campana $^{\text {c }}$ \\ ${ }^{a}$ University of Bern, Institute of Geological Sciences, 3012 Bern, Switzerland - zapp@ geo.unibe.ch \\ ${ }^{\mathrm{b}}$ Swiss Federal Institute for Forest, Snow and Landscape Research WSL, 8903 Birmensdorf, Switzerland - \\ (alexander.beer, jens.turowski)@wsl.ch \\ ${ }^{c}$ University of Bern, Institute for Forensic Medicine, Bühlstrasse 20, 3012 Bern, Switzerland - \\ lorenzo.campana@irm.unibe.ch
}

Commission V, WG V/6

KEY WORDS: close range photogrammetry, structured light, geomorphology, erosion

\begin{abstract}
:
While long term erosion rates of bedrock material may be estimated by dating methods, current day erosion rates are - if at all available - based on rough estimates or on point measurements. Precise quantification of short term erosion rates are required to improve our understanding of short term processes, for input in landscape evolution models, as well as for studying the mechanics and efficiency of different erosion processes in varying geomorphological settings. Typical current day erosion rates in the European Alps range from sub-millimetre to several millimetres per year depending on the dominant erosion processes. The level of surveying accuracy required for recurring sub-millimetre to millimetre measurements in the field is demanding. A novel surveying setup for insitu measurement of bedrock erosion was tested recently in three different locations in Switzerland. Natural bedrock was investigated in the Gornera gorge close to Zermatt. Further on, bedrock samples were installed in exposed locations in the Erlenbach research watershed close to Einsiedeln, and in the Illgraben debris flow channel, located in the Canton Schwyz and Valais, respectively. A twofold measurement approach was chosen for all locations. For the first setup control points providing an absolute reference frame for recurrent measurements were embedded close to the area of interest. Close range photogrammetry was applied to measure surface changes on the bedrock samples. The precision for surface measurements in the field was $0.1 \mathrm{~mm}(1 \mathrm{\sigma})$ and thus suitable for the application. The equipment needed for the surveys can easily be carried to the field. At one field site a structured light scanner was used along with the photogrammetric setup. Although the current generation of structured light scanners appeared less suitable for field application, data acquisition was much faster and checking the data for completeness in the field was straight forward. The latest generation of compact structured light scanners will probably be most suitable for similar applications.
\end{abstract}

\section{INTRODUCTION}

\subsection{Objectives}

"An objective and quantitative in-situ measure of rock erodibility over appropriate length scales is badly needed" (Whipple, 2004). While long term erosion rates may be estimated by dating methods (Quigley et al., 2007), current day erosion rates are - if at all available - based on rough estimates or on point measurements. Precise quantification of short term erosion rates are required to improve our understanding of short term processes, for input in landscape evolution models, as well as for studying the mechanics and efficiency of different erosion processes in varying geomorphological settings (Hancock et al., 1998). Typical current day erosion rates in the European Alps range from sub-millimetre to some millimetres per year (Wittmann et al., 2007) depending on the dominant erosion processes.

Recurrent measurement of bedrock surfaces in Alpine environments is quite demanding. A stable reference frame has to be installed and surveyed with very high accuracy. The measurement equipment should not only be very precise, but also lightweight and compact as it has to be carried to the field sites.

\footnotetext{
* Corresponding author.
}

\subsection{Study sites}

The developed methodology was applied in three different field settings. Rock samples were installed in the Illgraben debris flow channel near Leuk (Canton Valais, at $800 \mathrm{~m}$ a.s.1.) and the Erlenbach catchment close to Einsiedeln (Canton Schwyz, at $1100 \mathrm{~m}$ a.s.1.). Discharge is monitored in both catchments and the rock samples are easily accessed. The third test site is the Gornera torrent (2000 m a.s.l.) located above the city of Zermatt (Canton Valais). In the latter location abrasion was measured on a large block located in the torrent. Discharge and sediment flux were monitored by a hydropower company at this location.

The Illgraben catchment contains one of the most active debris channels in Europe. Over the last years three to five debris flows per year occurred (McArdell et al., 2007). Debris flows reach a volume of up to $30^{\prime} 000 \mathrm{~m}^{3}$ per event (summer 2010). Rock samples were placed in a concrete block and fixed to a check dam in the centre of the debris flow channel (Figure 1). The placement was below the crest of the check dam as a similar installation was carried away during the previous field season. Dimensions of the samples was $0.2 \times 0.2 \times 0.2 \mathrm{~m}^{3}$. The rock samples represented three different lithologies - marble, granite, and sandstone - with different grain size, different hardness, and different texture. While grain size and hardness will have an impact on the recorded abrasion rate, texture of the 


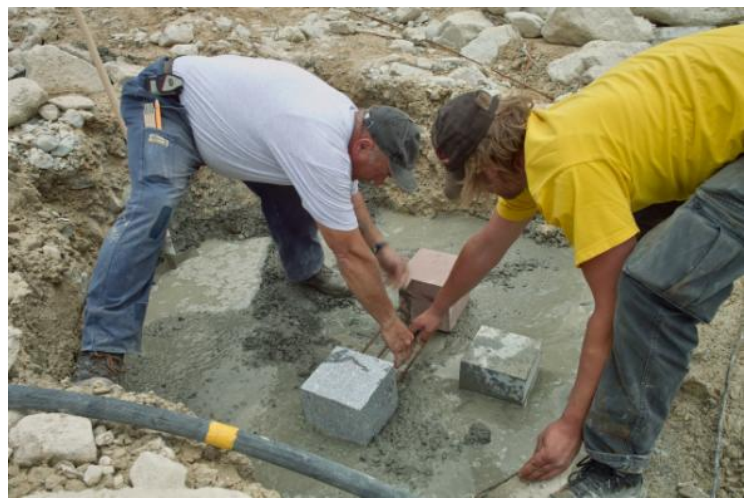

Figure 1. Installation of rock samples at the Illgraben site.

rock samples plays an important role for identification of homologous points using stereo photogrammetry. The expected abrasion in this environment was assumed to be more than a millimetre per event and thus much larger than the average denudation rate in the European Alps. Rock samples were installed in June 2010. Measurements took place $8^{\text {th }}$ July 2010 and $3^{\text {rd }}$ August 2010 after a large debris flow event. The rock fragments were covered by half a metre of debris allowing for an independent measurement epoch after the debris flow. During the next field season a new set of rock samples was installed level with the check dam to measure erosion. Since installation in summer of 2011, no significant debris flow event occurred. Data for comparison will be collected during the upcoming field season in 2012.

The installation in the Erlenbach catchment took place in May 2011. Water flow can be diverted during measurement epochs allowing for more frequent measurements. At this location two $0.36 \times 0.50 \mathrm{~m}^{2}$ rock samples - concrete and marble - were fixed in the flow path. Surface measurements were taken on different dates. The Erlenbach catchment is equipped with monitoring instrumentation including a power line with outlet near the area of interest. Therefore, a structured light scanner has also been used for one epoch in addition to the photogrammetric setup. Consequently, data of both acquisition techniques can be compared to each other.

Two epochs from the Gornera field site (Figure 2) are available from the field season of 2011. Only the photogrammetric technique was applied in this location. The shape of the block and the much larger surface area compared to the other field sites required many more images for a detailed stereo analysis.

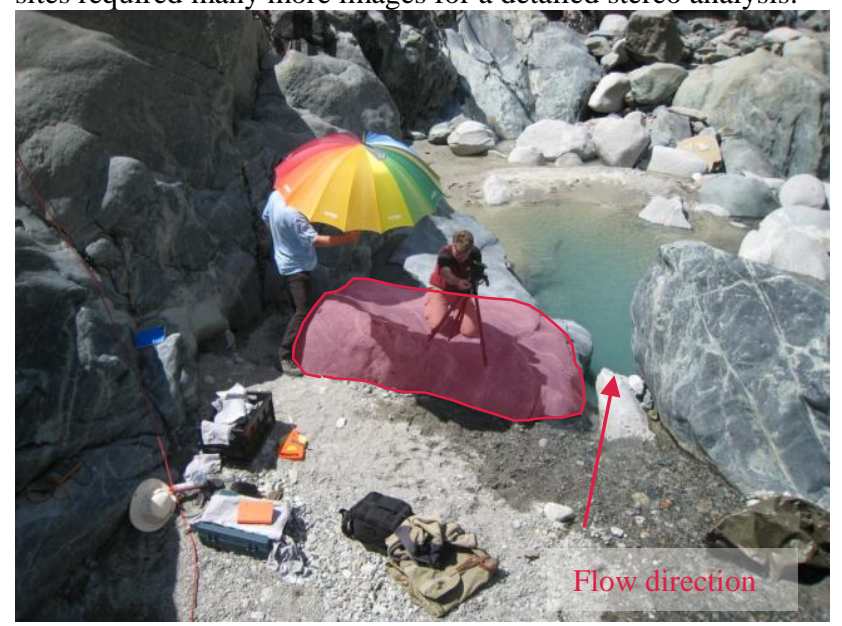

Figure 2. Data acquisition at the Gornera field site.

\section{DATA ACQUISITION}

\subsection{Close range photogrammetry}

Before measurements could start, a network of reference points was defined. Several target holders for reference markers were either embedded in the concrete (Erlenbach, Illgraben) or put in holes drilled in the block (Gornera). FTI brass target holders (manufactured by Hubbsmachine) allowed covering the reference points between measurement epochs. Targets were placed deeper than the surface so the top of the FTI target holder could be covered with cloth, pebbles and injection mortar for protection between epochs. A redundant number of FTI targets were installed and most of the targets were recovered after an event. In some cases, targets were seriously damaged trying to reopen them or because construction mortar penetrated into the target so that the cap was stuck. The long term durability of the targets may be judged when revisiting the field sites for the 2012 field season.

Close range photogrammetry was used for definition of a coordinate reference frame (Figure 3). Targets were placed in the FTI holders and up to 120 coded targets were distributed in the area of interest. At least two scale bars with a stack up accuracy of $0.02 \mathrm{~mm}$ (Brunson) were placed in the area of interest for scaling of the photogrammetrically derived coordinate system. At least 25 images were taken with an Alpa 12 Metric camera and Leaf Aputs digital camera back (RiekeZapp, 2010). Coordinates of the reference points were calculated using a self-calibrating bundle block adjustment in Aicon 3D Studio software (Aicon, 2011). Two different focus setting were used for image acquisition (Figure 4). The images taken further away covered many coded target points per image while the image taken from closer range had much higher resolution and were later used for stereo image matching. The two focus settings of the camera were introduced as two individual cameras in the adjustment.

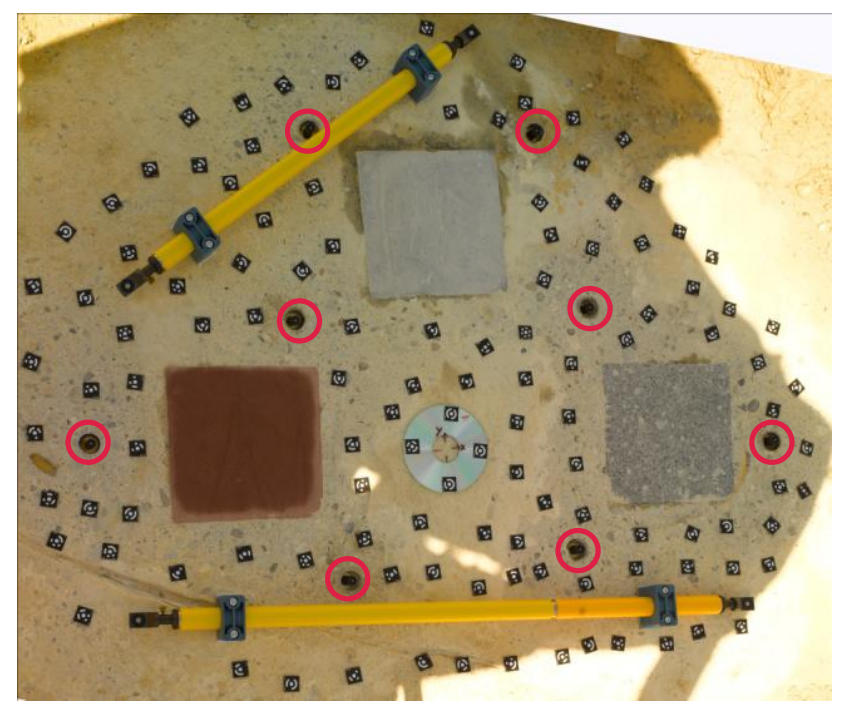

Figure 3. Photogrammetric setup for surveying of the targets at the Illgraben field site. Eight FTI target holders were embedded in the concrete (locations marked in red).

The same procedure was repeated for each measurement epoch. The precision of the target coordinates from one epoch to the next was estimated by using a Helmert transformation with the scale parameter fixed to unity in Aicon 3D Studio software. This allowed for checking the overall precision of the reference 
coordinates as well detection of points that may have shifted between epochs. Transformation results at the Illgraben site revealed an overall RMS error of $0.025 \mathrm{~mm}$; the largest RMS error of a single point coordinate was $0.059 \mathrm{~mm}$. Similar results were accomplished for the other field sites.

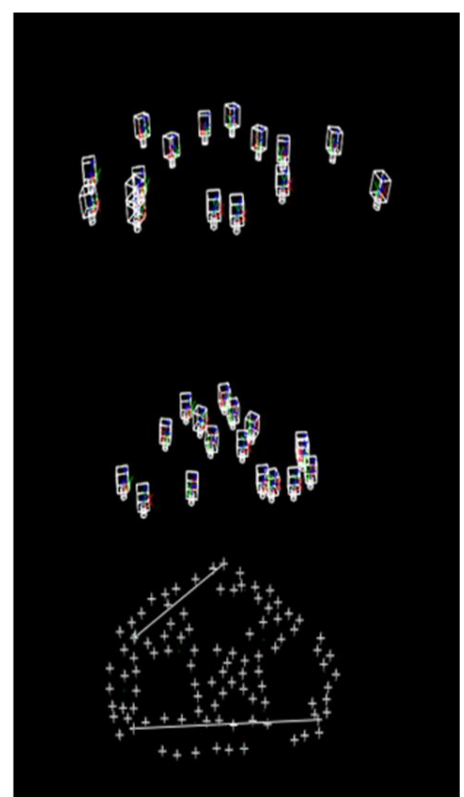

Figure 4. A combined bundle block adjustment was calculated to retrieve coordinates for the reference points as well as image orientation and camera geometry for two camera settings.

Close up imagery was imported in ERDAS/LPS 2010 software and pair wise image matching was performed. Images pairs were selected manually based on overlap and base distance between the images. A point cloud file was calculated from each stereo pair. The individual files were visually checked and merged using ArcGIS 10 software. Since the area of interest was typically covered in several stereo models, very dense point clouds were generated. The point clouds were combined and down-sampled to a raster with $0.5 \mathrm{~mm}^{2}$ cell size applying a local median filter. The amount of abrasion for each raster cell was calculated by subtracting the elevation rasters of two epochs (Figure 5).

\subsection{Structured light scanner}

A GOM ATOS III structured light scanner was used at the Erlenbach field site parallel to the photogrammetric workflow. While the generation of mass points was much more straight forward as compared to stereo matching of homologous points, the GOM scanner was heavier and bulkier than the camera equipment and required either a power generator or a power plug during data acquisition. The Erlenbach catchment was easily accessible and power for the GOM scanner was readily available.

The same reference points were used for the photogrammetric setup were also used for the structured light scanning. Coordinates for the GOM system were calculated on an image bundle adjusted with GOM TRITOP software (GOM, 2008).

The GOM scanner triangulates a dense mesh of $3 \mathrm{~d}$ points and allows checking for completeness as well as acquisition errors on the job. Individual mesh tiles were oriented and merged with GOM INSPECT v7 software (GOM, 2011).
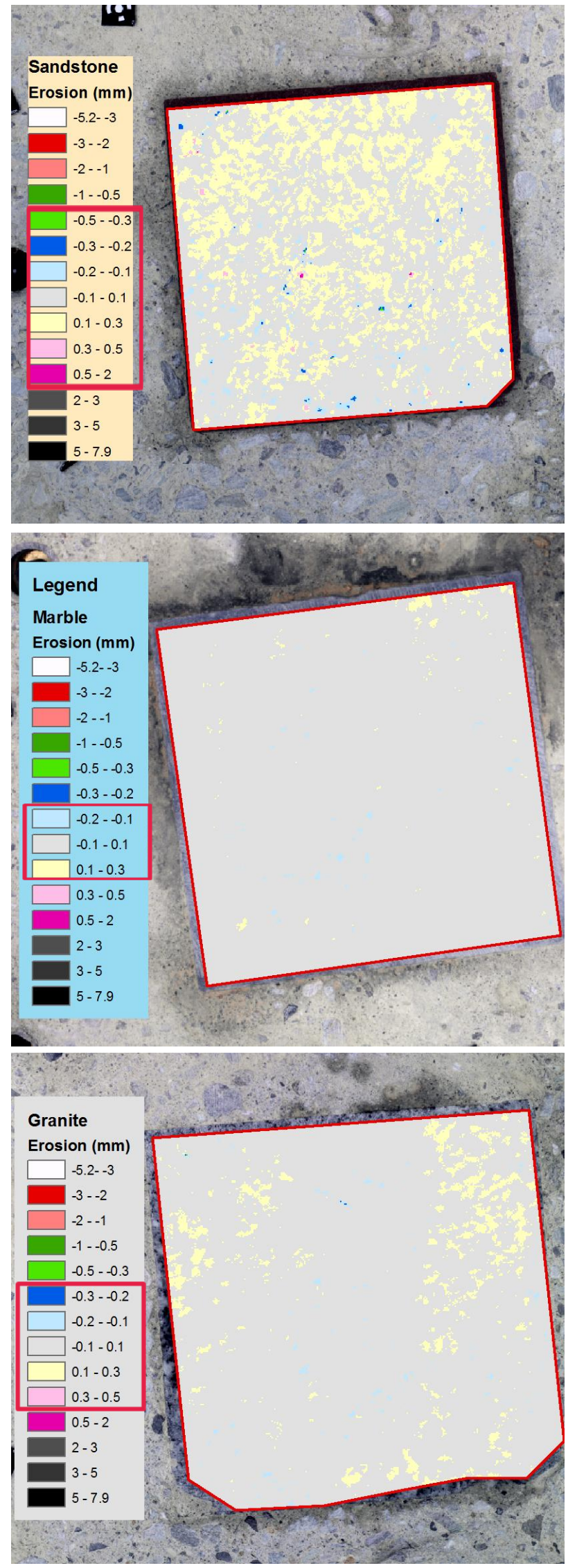

Figure 5. Difference DEMs comparing two epochs of measurements at the Illgraben site showing marginal erosion. 


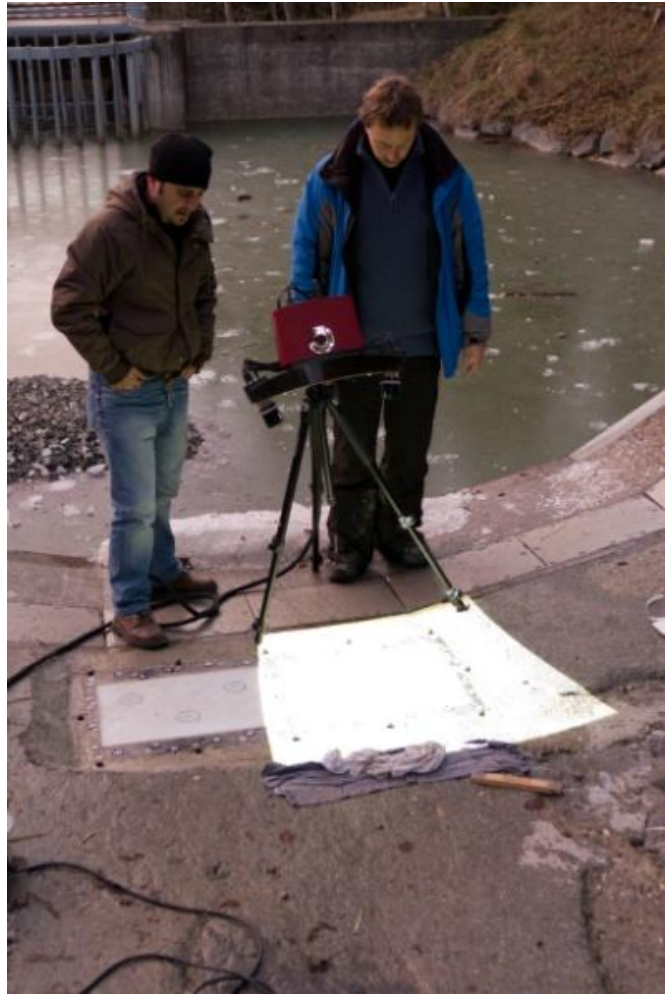

Figure 6. Structured light scanning at the Erlenbach site.

\section{RESULTS AND DICSCUSSION}

Results in Figure 5 and Table 1 reveal very little change on the surfaces at the Illgraben site. It is most likely that the rock samples were positioned too far below the active surface and were actually protected from erosion by the check dam. Assuming on the other hand that the rocks were not eroded, the results can be used to check the reproducibility of surface measurements between two epochs - including excavation after the debris flow. Assuming zero erosion, the standard deviation of the difference DEMs represented the precision of the analysis (Table 1). The largest standard deviation was well below 0.1 mm. All models show spots with larger elevation values compared to the previous epoch marking aggradation instead of erosion. The largest spot value for aggradation was $0.379 \mathrm{~mm}$. This is best explained by sub-optimum preparation of the surface before measurement as well as the possible import of windblown dust particles - although visible, the effect is marginal considering that the data was generated under field conditions. The average change in elevation was positive (erosion) for all three plates.

\begin{tabular}{|c|c|c|c|}
\hline $\begin{array}{c}\text { Difference } \\
\text { DEM }\end{array}$ & Granite & Marble & Sandstone \\
\hline Min. $(\mathrm{mm})$ & -0.379 & -0.187 & -0.369 \\
\hline Max. $(\mathrm{mm})$ & 0.219 & 0.203 & 0.647 \\
\hline Average $(\mathrm{mm})$ & 0.020 & +0.000 & 0.057 \\
\hline$\sigma_{\mathrm{Z}}(\mathrm{mm})$ & 0.051 & 0.037 & 0.076 \\
\hline
\end{tabular}

Table 1. Difference DEM of two epochs with no significant erosion, i.e. average difference less than standard deviation $\left(\sigma_{z}\right)$ of difference DEM.
A new set of rocks was installed level with the crest of the check dam. An initial surface measurement was recorded in summer of 2011. No debris flow went over that area in 2011, we expect new events in summer 2012.

The Erlenbach field site was surveyed twice on the same day by different operators starting the whole workflow from scratch each time. The difference DEM of the generated surfaces had a mean of $0.006 \mathrm{~mm}$ and a standard deviation of $0.070 \mathrm{~mm}$ indicating a similar level of reproducibility as for the Illgraben experiment. Measurements taken at the Erlenbach field site on $5^{\text {th }}$ and $18^{\text {th }}$ October 2011 captured a major flow event with 44 $\mathrm{m}^{3}$ of rock particles transported over the area of interest on $10^{\text {th }}$ October 2011. More than $99.9 \%$ of the surface indicated erosion, average erosion on the concrete surface was $0.8 \mathrm{~mm}$ (Figure 7). Maximum erosion at exposed areas was up to 4.1 $\mathrm{mm}$ while flat areas revealed erosion values between 0 and 1.0 $\mathrm{mm}$.
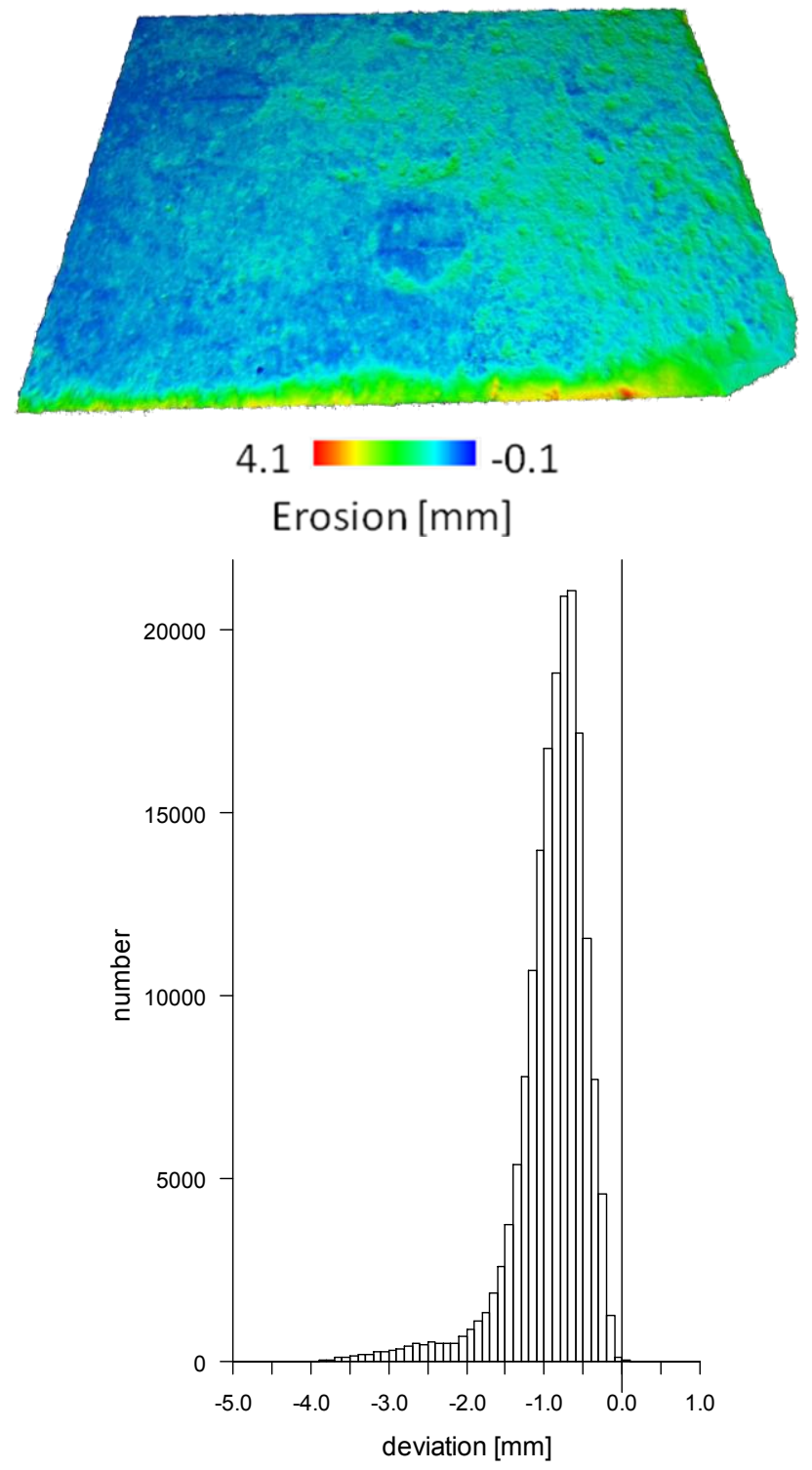

Figure 7. Difference DEM in oblique view and histogram of difference values before-after a large flow event at the Erlenbach field site. 
The structured light scanner was at the time of writing only used once at the Erlenbach field site (Figure $6 \& 8$ ). Data were collected at dawn as recommended for outdoor applications only the latest generation of structured light scanners is advertised as unsusceptible to sunlight. The structured light scanner may not be practical for field use in remote areas due to the bulky dimensions, weight and the need for an external power source, but the method revealed several advantages over the photogrammetric setup. The major advantage was the speed of data acquisition and processing. A single scan was sufficient for capturing a complete rock plate with sub-millimetre resolution. Elevation values were collected for each camera pixel and results could be checked for completeness in the field. The active projection system of the structured light scanner Texture on the marble surface was hardly sufficient for photogrammetric stereo matching. In case of the structured light method texture was projected on the surface allowing easy data capture. Although data capture on the marble surface was straight forward, the resulting surface may not necessarily represent the true surface as light may penetrate to subsurface layers of the marble.
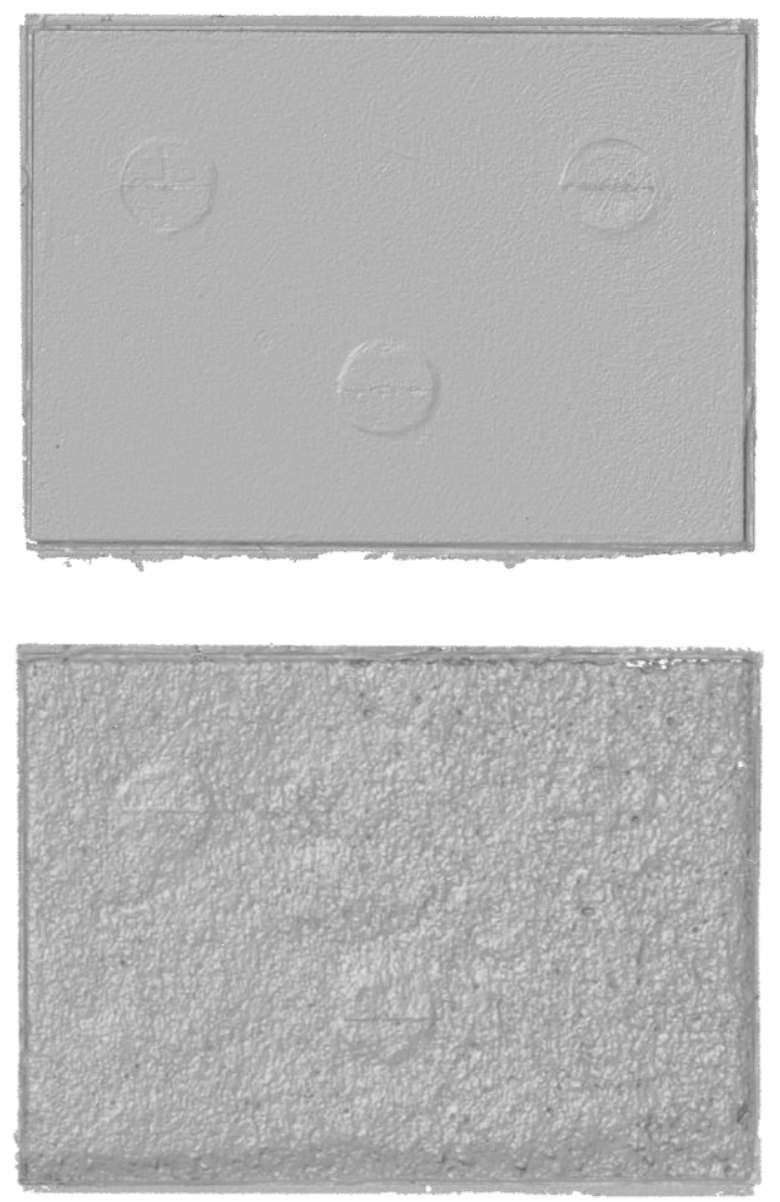

Figure 8. Structured light scanning results at the Erlenbach site. The top model shows the marble surface, the bottom model represents a concrete surface which at this point already showed erosion marks.

\section{CONCLUSIONS}

The photogrammetric method produced data with sufficient precision for in situ measurement of bedrock erosion in the field. Precision $(1 \sigma)$ of the resulting DEM was found to be better than $0.1 \mathrm{~mm}$. The methodology was tested at three different field sites.

Collection of surface data with a structured light scanner was also successful, but the device was not practical for field use in remote areas. The latest generation of structural light scanners should allow scanning in daylight conditions and offer more compact dimensions in order to overcome current shortcomings. Rock lithology had an impact on the point density and probably on measurement precision. The photogrammetric method required texture on the rock surface for identification of homologous points for stereo matching. The structured light approach was an active remote sensing technique adding texture to the surface by light projection.

Experiments and field data acquisition will be continued and data will be used for input in sediment transport and erosion models for a better understanding of surface processes.

\section{REFERENCES}

Aicon, 2011. Aicon 3D Studio - User Manual on CD-ROM.

GOM, 2008. TRITOP - User Manual on CD-ROM.

GOM, 2011. INSPECT - User Manual on CD-ROM.

Hancock GS, Anderson RS, WhippleKX., 1998. Beyond power: bedrock river incision process and form. In: Tinkler, K, Wohl; E.E., 1998, Rivers Over Rock: Fluvial Processes in Bedrock Channels. Washington, DC: Am. Geophys. Union 35-60.

McArdell, B. W., Bartelt, P. \& Kowalski, J., (2007): Field observations of basal forces and fluid pore pressure in a debris flow. Geophysical Research Letters, 34(7).

Quigley, M., Sandiford, M., Fifield, K., Alimanovic, A., 2007. Bedrock erosion and relief production in the northern Flinders Ranges, Australia. Earth Surf. Process. Landforms; 32:929-944.

Rieke-Zapp, D., 2010. A digital medium format camera for metric applications - Alpa 12 Metric. The Photogrammetric Record, 25(131): 283-298.

Wittmann, H., von Blanckenburg, F., Kruesmann, T., Norton, K.P. \& Kubik, P., 2007. The relation between rock uplift and denudation from cosmogenic nuclides in river sediment in the Central Alps of Switzerland. J. Geophys. Research, 112: F04010.

Whipple, K.X., 2004. Bedrock rivers and the geomorphology of active orogens. Annu. Rev. Earth Planet. Sci.; 32: S. 151-185. 